Revista de Economia Política, vol. 31, no 3 (123), pp. 370-380, julho-setembro/2011

\title{
Os fluxos de IDE no Brasil nos anos 1990: uma revisão de literatura à luz das transformações em curso
}

\author{
NILSON MACIEL DE PAULA* \\ TEREZINHA SARACINI CIRIELLO MAZZETTO**
}

The flows of foreign investments in Brazil in the 1990s.

The flows of foreign investments in Brazil starting from the 1990s have called attention due to the magnitude of the invested value, the prevalence of properties acquisitions as a preferential way of carrying out these investments, and for the primacy of the operations involving rivals companies. This article searches for an explanation for the cycle of foreign direct investment flows, which is happening in Brazil. Arguments were reconsidered on the existence of sole assets and the advantages of property and control as a basis for carrying out overseas investments, and to explicit their link with the M\&As.

Keywords: investments; mergers; acquisition.

JEL Classification: F00; F2; L1.

\section{INTRODUÇÃO}

O retorno dos fluxos de investimento direto estrangeiro (IDE) é o principal traço da economia brasileira no período recente.

Os investimentos externos direcionados ao Brasil cresceram significativamente ao longo da década de 1990, atingindo o patamar mais elevado no ano 2000, quando o país recebeu US\$29.876,37 bilhões. As privatizações tiveram uma participação importante no volume total de recursos recebidos nesse período, mas, a partir de 2001 os fluxos de IDE cresceram enquanto os montantes direcionados às

\footnotetext{
* Professor da Universidade Federal do Paraná (UFPr). E-mail: nilson@ufpr.br. Professora da Universidade Estadual de Londrina (UEL). E-mail:saracini@uel.br. Submetido: Abril 2009; Aprovado: Dezembro 2009.
} 
privatizações foram substancialmente reduzidos (Sobeet, 2008, p. 1). Novos recordes foram registrados em 2007 e 2008, com a entrada de US\$33.704,58 bilhões e de US\$ 43.886,30 bilhões, respectivamente (Banco Central do Brasil, 2009).

Além dos valores sem precedentes chama a atenção a importância das fusões e aquisições (F\&As) como forma de condução dos investimentos externos e, o predomínio das operações envolvendo empresas que atuam no mesmo tipo de negócio (F\&As horizontais), como tem sido salientado em vários trabalhos.

Diante do exposto, a internacionalização produtiva constitui o objeto de estudo deste artigo, cujo foco é o atual ciclo de investimento direto estrangeiro no Brasil, iniciado nos anos 1990. O trabalho tem como objetivo reavaliar argumentos tradicionais encontrados na literatura, levando em conta o novo contexto em que os IDE estão ocorrendo. Assim, após o reexame de um conjunto de teorias, foi construída uma proposta analítica fundamentada na Organização Industrial.

A metodologia desta pesquisa que se propõe a confrontar dados históricos e referenciais teóricos é necessariamente bibliográfica e analítica e requer a consulta de documentos e bases de dados. A principal fonte é o Banco Central do Brasil que disponibiliza as informações relevantes, ainda que outras também sejam utilizadas.

O artigo está estruturado em duas seções, além desta introdução. A primeira analisa os fluxos de IDE direcionados ao Brasil a partir de 1990 e descreve o quadro em que ocorreu o retorno dos recursos externos. A segunda discute o papel do IDE no processo de expansão das firmas no contexto das políticas de atração de investimentos adotadas por vários países recentemente, e procura explicitar a ligação entre investimento direto estrangeiro e as fusões e aquisições.

Algumas conclusões são apresentadas ao final do artigo.

\section{A RETOMADO DO IDE, NO BRASIL, NOS ANOS 1990: CONDICIONANTES}

A expansão dos investimentos externos em curso no Brasil teve início em 1990, quando foram adotadas medidas para promover o ajuste às novas condições prevalecentes na economia mundial consubstanciadas na globalização dos mercados.

A mudança nos condicionantes macroeconômicos, que seria promovida através de um programa ${ }^{1}$ associando reforma comercial, liberalização e desregulamentação da economia brasileira, começou nos primeiros anos da década de 1990.

A primeira fase do ajuste envolveu uma reforma comercial cujo objetivo era

\footnotetext{
${ }^{1}$ Tratava-se da introdução de reformas políticas "voltadas ao mercado" como resposta à crise dos anos 1980. O programa seguia a orientação neoliberal que, deveria, necessariamente, incluir disciplina fiscal, minimização das distorções do sistema de preços doméstico e formas de assegurar a observação de regras de livre mercado (Baumann, 2001).
} 
o de aprofundar a reformulação da estrutura tarifária iniciada em $1988,{ }^{2}$ complementando os resultados parciais já alcançados. Quanto aos resultados pode-se dizer que o cronograma da reforma proposta em 1990 foi cumprido. Em 1991, a maior parte das alíquotas eram inferiores às determinadas pela Reforma de 1988. A proteção efetiva (média ponderada pelo valor da produção) na indústria de transformação passou dos 57,8\% vigentes em 1988 para 24,6 \%, em 1994. Observou-se, também, uma menor dispersão e variabilidade das alíquotas por gênero da indústria, expressando maior uniformidade tarifária (Almeida, 1996, pp. 96-97).

Concomitantemente, frequentes desvalorizações cambiais foram necessárias para conter as importações estimuladas pelas tarifas mais baixas. Os efeitos do aumento dos preços dos itens importados na balança comercial seriam compensados pela entrada de capitais externos. Para atingir esse objetivo foram realizadas modificações na legislação e no sistema de regulamentação.

Uma das principais medidas foi a eliminação da distinção entre empresa estrangeira e nacional, estabelecida legalmente. Outra foi a liberalização conta de capitais. Nessa direção foi determinada a isenção do imposto de renda incidente nos lucros e dividendos remetidos ao exterior pelas filiais de empresas estrangeiras, a eliminação de várias restrições à propriedade intelectual, e liberação da remessas de royalties incidentes sobre marcas e patentes pertencentes a empresas estrangeiras (Rocha, Iooty, Ferraz, 2001; Toonoka, 1998).

A entrada de capital externo no Brasil também seria estimulada pelo processo de integração regional, com a assinatura do tratado para criação do Mercado Comum do Cone Sul (Mercosul), em 1991. O acordo estabeleceu uma tarifa comum de proteção para um elevado número de produtos, ${ }^{3}$ estabelecida em $20 \%$. Até 2005 as tarifas convergiriam para uma tarifa externa comum (TEC), cujo limite proposto era de $35 \%$ para o conjunto dos produtos importados, respeitando o acordo negociado ao final da Rodada Uruguai do GATT (Farina, 1996, p. 6; Leite, 1996, p. 121).

A partir de 1994 a prioridade do ajuste da economia brasileira passou a ser o combate à inflação crônica que havia se instaurado no país. O programa de estabilização consubstanciado no Plano Real fundamentou-se na percepção de que a crise do Estado e a existência de um sistema de indexação formal e informal eram os principais responsáveis pelo processo inflacionário. O choque fiscal necessário

\footnotetext{
${ }^{2}$ A estrutura resultante do modelo de substituição de importações apresentava, ao final dos anos 1980, as seguintes características: a) tarifas altas e abundantes; b) abundância de regimes especiais; c) proliferação de controles quantitativos de importação; d) existência de tributos adicionais (Almeida, 1996, p. 171).

${ }^{3}$ Foram listados 2.500 produtos que teriam uma tarifa comum de proteção $(20 \%)$; para outros itens (399 produzidos no Paraguai, e 300 no Brasil, Argentina e Uruguai) a tarifa seria superior a 20\%. Até 2005, todos teriam uma tarifa comum (TEC), à exceção de computadores e telecomunicações (Farina, 1996, p. 6).
} 
para reduzir o déficit público seria complementado por políticas de renda. Assim, em vez de simplesmente procurar restringir a emissão de moeda que financiava o déficit governamental, foram adotadas medidas para garantir um rápido equilíbrio das contas públicas na primeira fase do plano, interferindo diretamente na formação das expectativas.

A criação de uma unidade real de valor (URV) constituiu uma segunda fase do plano, cujo objetivo era o de eliminar os mecanismos que produziam a inércia inflacionária. A URV exerceria, temporariamente, a função unidade de conta até o lançamento da nova moeda (Real), após o período de adaptação das expectativas dos agentes. Essa seria a terceira e última fase do Plano Real.

O câmbio exerceria um papel fundamental na estratégia de combate à inflação, funcionando como uma âncora nominal dos preços. Esperava-se que a valorização cambial, ao estimular as importações, ajudaria a conter os frequentes aumentos dos preços domésticos.

A despeito da coerência dessa política cambial, sabia-se que, no curto prazo, a valorização associada à política de abertura comercial dos anos 1990 geraria déficits comerciais crescentes, devido à elevação do coeficiente importado. Entretanto, esperava-se que, no longo prazo, a maior eficiência sistêmica, o menor custo da reestruturação e a estabilidade monetária viabilizariam a expansão do investimento privado nacional e estrangeiro (Miranda e Martins, 2000).

Assim, após décadas de descontrole inflacionário o programa adotado a partir de 1994 conseguiu reduzir o índice de preços ao consumidor, de $2.940 \%$ (média anual) em 1990 para 35\%, em 1995 (Farina, 1996, p. 24).

A estabilização dos preços aliada as políticas visando à retirada de obstáculos ao investimento estrangeiro foi crucial para o retorno dos fluxos de IDEs, na magnitude registrada a partir dos anos 1990, no Brasil.

Após a abrupta interrupção do ingresso de investimento direto estrangeiro nos anos 1980, o Brasil voltou a fazer parte dos planos de investimentos das empresas estrangeiras.

Entre 1996 e 2000, por exemplo, o país recebeu investimentos diretos estrangeiros na ordem de US\$ $103.688,03$ bilhões, ou seja, duas vezes e meia o valor do estoque apurado no Censo de 1995. De 2001 a 2006, o ingresso apresentou crescimento de $12,59 \%$ e o total recebido atingiu US\$116.740,62 bilhões (Banco Central do Brasil, 2008a e 2008 b, respectivamente), como se nota na Tabela 1. 
Tabela 1: Estoque e fluxos de IDE no Brasil, segundo os principais setores e ramos de atividade; estoque (1995); fluxos 1996-2000 e 2001-2006

\begin{tabular}{c|c|c|c|c|c|c}
\hline & & & \multicolumn{2}{|c|}{$\begin{array}{c}\text { Fluxos } \\
1996-2000\end{array}$} & \multicolumn{2}{|c}{$\begin{array}{c}\text { Fluxos } \\
2001-2006\end{array}$} \\
$\begin{array}{c}\text { Atividade } \\
\text { econômica }\end{array}$ & $\begin{array}{c}\text { Estoque } \\
\text { em 1995 } \\
\text { US\$ milhões }\end{array}$ & $\begin{array}{c}\text { Fluxos } \\
2007 \\
\text { US\$ milhões }\end{array}$ & $\begin{array}{c}\text { US\$ } \\
\text { milhões }\end{array}$ & $(\%)^{1}$ & $\begin{array}{c}\text { US\$ } \\
\text { milhões }\end{array}$ & $(\%)^{2}$ \\
\cline { 4 - 7 } & & $4.982,07$ & $1.780,93$ & 1,7 & $8.248,73$ & 7,0 \\
$\begin{array}{c}\text { Agricultura, } \\
\text { pecuária, } \\
\text { extrativa } \\
\text { mineral }\end{array}$ & 924,99 & $12.166,08$ & $18.632,54$ & 18,0 & $44.916,71$ & 38,4 \\
\hline $\begin{array}{c}\text { Indústria } \\
\text { Serviços }\end{array}$ & $12.863,54$ & $16.556,44$ & $83.274,49$ & 80,3 & $63.848,17$ & 54,6 \\
\hline Total & $41.695,62$ & $33.704,58$ & $103.688,03$ & 100,0 & $116.740,62$ & 100,0 \\
\hline
\end{tabular}

FONTE: adaptação das tabelas do BACEN: estoque em 1995 e fluxos de 1996 a 2000; fluxos de 2001 a 2006 ; fluxos a partir de 2007 (BANCO CENTRAL DO BRASIL, 2008a, 2008b, e, 2009, respectivamente). (1) Percentual do estoque de IDE do setor em relação ao total, e do ramo de atividade no total do setor; (2) Percentual do fluxo de IDE do setor em relação ao fluxo total, e do ramo de atividade em relação ao total do setor.

Quanto à forma de realização desses investimentos há indícios do predomínio das aquisições patrimoniais em relação aos "novos" investimentos. De acordo com Miranda (2001, p. 234), em média, 65\% dos IDEs realizados no Brasil entre 1993 e 1998 ocorreram por meio de F\&As. De fato, quando se analisa a evolução das operações domésticas vis-à-vis às transfronteiras constata-se a primazia das últimas sobre as primeiras, em quase todos os anos do período 1994 a 2006, retratado no Gráfico 1.

Gráfico 1: Evolução das transações de

fusões e aquisições no Brasil - 1994 a 2006

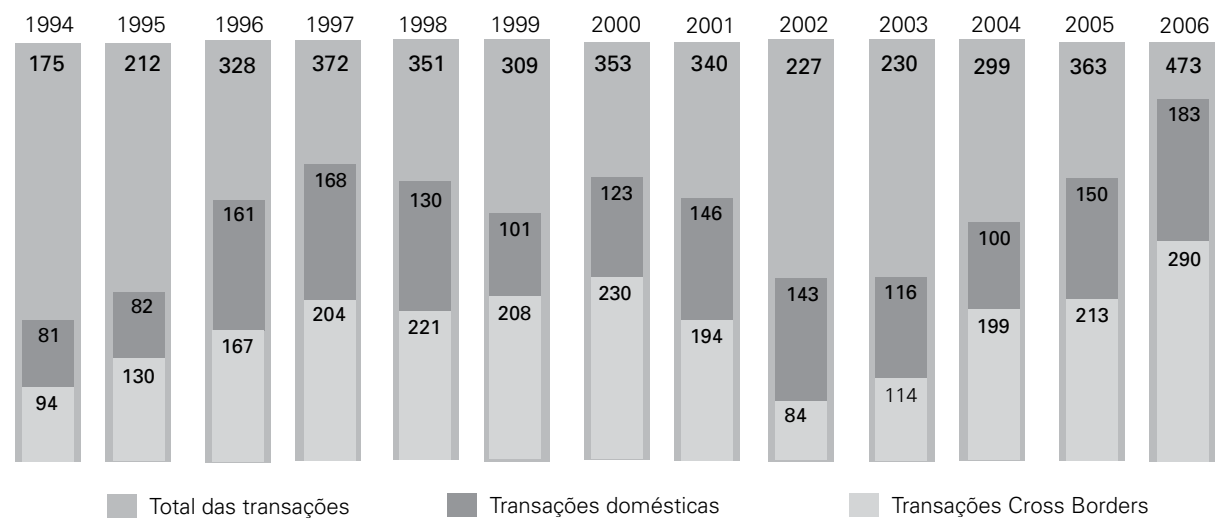

Fonte: KPMG (2001) 
Esse fenômeno que está ocorrendo no Brasil confirma a tendência identificada pela Unctad (2001), que interpretou a forte correlação entre IDE e F\&As como evidência do predomínio das aquisições patrimoniais como forma preferencial de condução dos investimentos externos, notadamente a partir dos anos 1990.

O grande número de F\&As realizadas no Brasil permite uma distinção entre o padrão dos investimentos realizados a partir dos anos 1990 em relação ao que ocorria anteriormente, quando predominava a construção de novas plantas (Miranda, 2001).

Diante do cenário delineado nesta seção, é importante reexaminar o papel do investimento direto estrangeiro na trajetória das firmas, levando-se em conta as condições em que está ocorrendo.

\section{O CONCEITO DE INVESTIMENTO DIRETO ESTRANGEIRO E DA EMPRESA QUE O REALIZA}

Com a crescente disseminação das empresas multinacionais, a partir dos anos 1960, o conceito de investimento direto estrangeiro tem sido constantemente reformulado. De uma perspectiva ampla, IDE se refere à transferência de capacidade produtiva e controle de ativos a partir do país sede para outros, através da realização de investimentos novos ou da aquisição de ativos de outras empresas (F\&As). A entidade que realiza IDEs passa a ser "multinacional", definida por Vernon (1966) como uma grande empresa, cuja expansão levou à instalação de filiais em pelo menos seis países. Discussões posteriores reduziram esse número, dando destaque ao simples deslocamento no limite de relação bilateral.

Considerando-se o grau de aprofundamento que o processo de internacionalização tem alcançado, o termo transnacional é o mais adequado para evidenciar a natureza da empresa que realiza investimentos no exterior.

Chesnais, se reportando a Michalet (1985, apud Chesnais, 1996, p. 73), chamou a atenção para algumas das características da empresa transnacional: a) ela é produto do processo de concentração e centralização do capital que a tornou "grande" no plano nacional; b) em geral, passou por um processo de diversificação produtiva antes de iniciar sua internacionalização; c) tem uma origem nacional, de modo que suas estratégias e sua competitividade envolvem os pontos fortes de sua base nacional e o auxílio advindo do Estado; d) é, em geral, parte de um grupo contemporaneamente estabelecido como uma holding internacional; e) a atuação da empresa ou do grupo, em escala mundial, leva à definição de estratégias e da constituição de uma determinada organização para isso.

O significado de grande empresa, como pondera Martinelli Júnior (1999), além de associado à eficiência econômica incorpora aspectos relativos à expansão das fronteiras de acumulação do grande capital, considerando três dimensões. A primeira se refere ao poder econômico que caracteriza a grande empresa, capacitando-a como líder em vários aspectos. A segunda diz respeito ao tipo de organização administrativa e funcional, dada por um "governo central" que articula as políticas 
e as atribuições das unidades produtivas. A terceira dimensão se relaciona à progressiva internacionalização produtiva da grande empresa ao longo da evolução capitalista.

A concepção de empresa internacional aqui delineada reforça a visão de entidade voltada à produção, não apenas voltada às trocas internacionais, como já havia ressaltado Hymer $(1960)^{4}$. A crescente ênfase à natureza da transnacional como empresa voltada à produção internacional reforça a importância do investimento direto estrangeiro e seu papel no processo de crescimento das firmas. Nesse sentido, "[...] o IDE designa um investimento que visa adquirir um interesse duradouro em uma empresa cuja exploração se dá em outro país que não o do investidor. O objetivo deste último é influir efetivamente na gestão da empresa em questão" (Chesnais, 1996, p. 55).

A teoria tradicional procura explicar o crescimento da firma capitalista, supondo inicialmente que ela atua em um país de economia fechada. Como decorrência desse suposto, há um momento em que a acumulação de capital atinge um nível a partir do qual o montante de capital e de lucros gerados já não é absorvido no interior da indústria e/ou do mercado doméstico em que a firma opera.

Nessa circunstância, a demanda do mercado corrente se revela insuficiente para assegurar a realização do potencial de crescimento da firma. As restrições ao crescimento se manifestam primeiramente no plano da indústria, e a diversificação das atividades surge como a principal opção estratégica da firma. $\mathrm{Na}$ medida em que se reduzem as possibilidades de expansão em seu próprio mercado via diversificação produtiva, a superação das restrições ao crescimento da firma induz a entrada em outros mercados e, posteriormente, em mercados de outros países. Nessas condições, a ampliação das operações pode ocorrer através do desenvolvimento de capacidade produtiva (localmente) para suprir mercados nacionais em que a firma não participava, ou através da compra de ativos (F\&As).

A inserção em mercados externos também pode ocorrer pela via da exportação de mercadorias. Contudo, a competição oligopolística impõe a necessidade de substituição da exportação de mercadorias pela exportação de capitais (Guimarães, 1982). O investimento de uma firma na produção local em um determinado país induz um movimento similar por parte dos demais competidores, como está ocorrendo na fase atual de internacionalização produtiva das empresas.

O impulso em direção aos mercados externos é, então, o resultado da dinâmi-

\footnotetext{
${ }^{4}$ Essa mudança traz importantes implicações, pois o investimento direto difere do comércio em vários aspectos: 1) por não ter a natureza de liquidez imediata (pagamento à vista) ou diferida (crédito comercial) o IDE apresenta uma dimensão intertemporal. Assim, enquanto o comércio se reduz a uma transação pontual, o investimento direto cria vários e sucessivos fluxos, pela transferência de capital e transferência de ativos (gera direito patrimonial); 2) os fluxos criados a partir da realização das inversões externas, especialmente de produção, comércio e de lucros, mantêm-se por diversos períodos e são menos vulneráveis às flutuações que afetam as transações comerciais; 3) a interrupção das atividades ("desinvestimento") de empresas transnacionais em algum mercado acarreta custos irrecuperáveis (sunk costs) (Bourguinat, 1992).
} 
ca de indústrias oligopolistas, cujo potencial de crescimento é significativamente superior às taxas de expansão de seus mercados domésticos. A concorrência exerce pressões para que as firmas busquem mercados mais amplos.

A argumentação proposta neste artigo é de que o contexto em que está ocorrendo a atual fase de internacionalização produtiva reforça a natureza do IDE como necessidade do próprio processo de expansão. A redução das barreiras ao capital internacional nas três últimas décadas aumentou drasticamente a pressão pela busca de novos mercados.

Como foi ressaltado por Chesnais (1996), o processo de expansão em direção aos mercados externos se tornou uma avalanche na medida em que cada grande grupo passou a entender as novas regras do jogo e, consequentemente, a aumentar seus investimentos no exterior. As novas regras se referem às políticas que passaram a ser adotadas pelos países a partir dos anos 1980 e que foram essenciais para a expansão da produção internacional na magnitude em que vem ocorrendo.

Sem as políticas pró-mercado o capital internacional e os grandes grupos transnacionais não teriam conseguido destruir tão depressa e tão radicalmente os entraves e freios à liberdade de se expandirem à vontade e de explorarem os recursos econômicos, humanos e naturais, onde lhes fosse conveniente (Chesnais, 1996).

Em suma, essas políticas aumentaram a pressão que induz o movimento em direção aos mercados externos reforçando uma necessidade decorrente da própria natureza da firma capitalista, como foi proposto por Penrose (1959), ${ }^{5}$ em sua abordagem pioneira.

De acordo com essa autora as empresas têm uma propensão ao crescimento que é determinada pela existência de serviços produtivos ociosos (tecnológicos, de escala, produtivos, e alguns de natureza dinâmica). O processo de expansão reduz essa ociosidade que é uma característica da firma capitalista, gerando "economias" de duas ordens: a) ganhos derivados das plantas já existentes, provenientes de economias de escala, técnica e administrativa; b) ganhos derivados da expansão, como vantagens de custo em criação de demanda, política de marketing, dentre outros.

Dessa ótica, a realização de investimentos em mercados externos é uma decorrência da expansão da empresa no âmbito do mercado doméstico. No processo de expansão em direção a outros países uma das principais dificuldades advém do conhecimento privilegiado das firmas nacionais em relação ao ambiente em que operam. Se, ainda assim, ocorre investimento estrangeiro devem existir contrapartidas. Quer dizer, a companhia estrangeira somente consegue entrar no mercado e realizar investimentos porque possui algum tipo de atributo que compensa a maior exposição aos riscos e incertezas do ambiente.

É à posse de um conjunto de ativos específicos ou únicos (unique assets) que viabiliza a realização dos IDEs, e que confere uma série de "vantagens de proprie-

\footnotetext{
${ }^{5}$ Penrose (1959) foi pioneira em estabelecer uma relação entre a capacidade de organização da firma e seu crescimento.
} 
dade". Essas vantagens estão associadas a economias de escala, ao conhecimento acumulado, à existência de sistemas de distribuição, controle de fontes de suprimentos, capacidade administrativa, dentre outros fatores (Penrose, 1959).

Através da transferência de seus ativos pela realização de investimentos diretos, as empresas estrangeiras movidas pela concorrência estendem suas vantagens sobre as nacionais. No enfoque dos ativos específicos, a própria dimensão da firma que se internacionaliza constitui um diferencial em relação às empresas que têm suas operações restritas ao país de origem. Quer dizer, o diferencial e base das vantagens de propriedade da empresa transnacional é o conjunto de ativos "únicos", exclusivos sob algum aspecto. $\mathrm{O}$ mecanismo pelo qual a firma mantém o controle destes ativos é o investimento direto estrangeiro.

O IDE pode ser conduzido pela via do crescimento interno ou do crescimento externo.

A primeira forma consiste no desenvolvimento de recursos produtivos no interior da firma, gerando um aumento do porte a partir da estrutura já existente, ou seja, ocorre pela internalização das atividades. Essa forma de crescimento pode levar à realização de investimento em mercados externos através da construção de facilidades (novas plantas), o chamado greenfield investment. Essa opção tem como motivação principal a possibilidade de escolher a composição dos ativos e sua alocação dentro da empresa, evitando os custos de transação e dívidas de outras empresas, inevitáveis nas negociações de fusões e aquisições (Ross, Westerfield e Jaffe, 2002).

A segunda consiste no aumento do patrimônio da firma por meio de fusões e aquisições ${ }^{6}$ e representa a possibilidade de aquisição total de um conjunto de meios de produção já combinados e em operação, ou a compra de participações em outras empresas. Essa forma de crescimento representa a possibilidade de redução imediata da pressão competitiva, na medida em que não há criação de nova capacidade no mercado em questão, mas apenas a transferência de propriedade dos ativos produtivos já existentes. Essa estratégia pode elevar o poder de mercado, particularmente através das F\&As horizontais, que propicia maior parcela de mercado à empresa adquirente (ou das empresas combinadas) e aumento da concentração (Ross, Westerfield e Jaffe, 2002).

No caso da opção por crescimento externo, ao recorrer às F\&As as empresas estrangeiras conseguem reverter vantagens que as nacionais detêm e que estão associadas ao maior conhecimento do ambiente e ao menor risco nas operações.

A partir da inserção externa essas vantagens somar-se-ão as vantagens próprias da empresa estrangeira fundamentadas em seus ativos específicos. A partir de seus recursos a empresa internacionalizada cria habilidades e às empregam para tirar proveito da experiência acumulada e se apropriar de lucros extras.

\footnotetext{
${ }^{6}$ Fusões consistem na celebração de um acordo legal entre duas firmas, no qual ambas renunciam à sua autonomia e passam a se submeter a um controle comum. Aquisições se referem à compra de uma firma (ou subsidiária) por outra. Neste caso, a empresa adquirida passa a se submeter ao controle da adquirente (Ross, Westerfield e Jaffe, 2002, pp. 653-654).
} 
Conforme a proposição de Hymer (1960), 7 o controle de uma subsidiária estrangeira permite a total apropriação dos retornos de certas capacidades e habilidades.

\section{CONCLUSÕES}

O artigo analisou os fluxos de investimentos diretos estrangeiros direcionados ao Brasil, a partir dos anos 1990, tendo por objetivo a proposição de uma interpretação para essa nova fase de internacionalização da economia brasileira.

A busca de uma explicação para esse fenômeno foi motivada por sua notoriedade, em função da magnitude dos investimentos externos, da forte correlação entre os IDEs e as F\&As, bem como o predomínio das operações de compra e venda envolvendo empresas concorrentes ( $F \& A s$ horizontais).

A partir dessas constatações a revisão da literatura explicitou a adequação do conceito de "transacional", no atual contexto demarcado pela adoção de uma conduta global pelas empresas. Essa concepção reforça o papel que as teorias tradicionais atribuem ao investimento direto estrangeiro no processo de expansão das firmas.

O IDE é a forma como as empresas conseguem manter o controle dos seus "ativos únicos”, os quais fundamentam as vantagens de propriedade das empresas estrangeiras sobre as domésticas. A opção por F\&As representa a possibilidade de que a empresa estrangeira consiga reverter vantagens que até então a empresa adquirida desfrutava, de um modo mais rápido do que a construção de novas plantas e/ou unidades produtivas.

A compra ou fusão representa um acréscimo no portfolio de ativos únicos, a partir dos quais a empresa transnacional se tornou grande, construiu sua liderança e a reputação em seu próprio território, e que são a base para a expansão em direção a outros mercados.

Nesse quadro, as políticas adotadas pelos países, especialmente a partir dos anos 1980, foram cruciais, na medida em que retiraram obstáculos ao capital internacional criando um ambiente extremamente favorável aos planos de investimentos das empresas.

Em suma, a perspectiva proposta no artigo é de que o avanço do processo de concentração e a consequente oligopolização do mercado são decorrências da posse de atributos únicos por parte de um grupo restrito de empresas. Como esse processo esbarra nas dimensões do mercado local, seu avanço induz à internacionalização produtiva, necessidade essa que tem sido significativamente acentuada pela mudança nos condicionantes macroeconômicos em curso.

\footnotetext{
7 "The control of a foreign subsidiary is desired in order to remove competition between that foreign enterprise and enterprises in other countries [...] or to appropriate fully the returns on certain skills and abilities" (Hymer, 1960, p. 25).
} 


\section{REFERÊNCIAS BIBLIOGRÁFICAS}

ALMEIDA, Eduardo Simões de (1996) "Mudança institucional e estrutural na economia brasileira do início dos anos noventa: uma abordagem evolucionista”. Dissertação (Mestrado em Economia) — Faculdade de Economia, Administração e Contabilidade, Universidade de São Paulo.

Banco Central do Brasil (2008a) "Investimento estrangeiro direto: tabelas - Censo 1995 e ingressos 1996 a 2000”. Disponível em: <http://www.bcb.gov.br/rex/IED/Port/ingressos/htms/index1. asp?idpai=invedir>. Acesso em: 10.3.2008.

Banco Central do Brasil (2008b) "Investimento estrangeiro direto: tabelas - Censos 1995/2000 e ingressos 2001 a 2006" Disponível em: <http://www.bcb.gov.br/rex/IED/Port/ingressos/htms/index2.asp?idpai=invedir $>$. Acesso em: 19.6.2008.

Banco Central do Brasil (2009) "Ingressos a partir de 2007", d. Disponível em:<http://www.bcb.gov. $\mathrm{br} / \mathrm{rex} / \mathrm{IED} /$ Port/Ingressos/planilhas/DivulgacaoAtividades07.xls $>$. Acesso em: 1.3.2009.

BAUMANN, Renato. (2001) "Brasil en los años noventa: una economía en transición", Revista de La Cepal, 73 (1): 148-172.

BOURGUINAT, Henri (1992) Finance Internationale. Paris: Press Universitaires de France.

CHESNAIS, François (1996) A Mundialização do Capital. São Paulo: Xamã.

FARINA, Elizabeth Maria Mercier Querido; SAES, Maria Sylvia Macchione (1996). "Food industry in Mercosur: many challenges and big opportunities". Paper presented at the International Seminar on Food, Agriculture and Agribusiness: future challenges and opportunities. Cirencester, UK.

GUIMARÃES, Eduardo A. (1982) Acumulação e Crescimento da Firma, Rio de Janeiro: Zahar.

HYMER, Stephen (1960) "The international operations of national firms: a study of direct foreign investment”, Tese (Doutorado em Filosofia) - Massachusetts Institute of Tecnhology, Cambridge.

KPMG (2001) "Fusões e aquisições no Brasil: análise dos anos 90". Disponível em: <http://www.kpmg. com.br/publicacoes/corporate_finance/structuredfinance/fa_90s.pdf>. Acesso em: 10.8.2007.

LEITE, Sérgio (1996) "Liberalização comercial e internacionalização; condicionantes à agricultura brasileira", Revista Estudos Sociedade e Agricultura,1 (7): 90-112.

MARTINELLI JÚNIOR, Orlando (1999) A Globalização e a Indústria Alimentar. Marília, Unesp; São Paulo: Fapesp.

MIRANDA, José Carlos; MARTINS, Luciano (2000) "Fusões e aquisições de empresas no Brasil”, Revista Economia e Sociedade, n. 14: 67-88.

MIRANDA, José C. (2001) “Abertura comercial, reestruturação industrial e exportações brasileiras na década de 1990”. Texto para Discussão IPEA 829.

PENROSE, Edith Tilton (1959) Foreign Investment and Growth of the Firm. Oxford: Basil Blackwell.

ROCHA, Frederico; IOOTY, Luciana; FERRAZ, João Carlos (2001) "Desempenho das fusões e aquisições na indústria brasileira na década de 90: a ótica das empresas adquiridas”, Revista de Economia Contemporânea, 5: 69-103.

ROSS, Stephen A.; WESTERFIELD, Randolph W.; JAFFE, Jeffrey F. (2002) Administração Financeira: Corporate Finance. São Paulo: Atlas, 2a. edição.

SOBEET Sociedade Brasileira de Estudos de Empresas Transnacionais e da Globalização Econômica (2009) "Recorde de US\$ 34,6 bilhões de ingressos de investimento direto estrangeiro (IDE) coloca Brasil na quinta posição entre países em desenvolvimento", Boletim Sobeet. ano VII, n. 52.

TOONOKA, Eduardo K. (1998) Investimento direto japonês na década de 80: uma análise dos seus determinantes no Brasil e no mundo. Tese (Doutorado em Economia) — Faculdade de Economia, Administração e Contabilidade, Universidade de São Paulo.

VERNON, Raymond (1966) "International investment and international trade in the product cycle", The Quarterly Journal of Economics, 80 (2): 190-207.

UNCTAD - UNITED NATIONS CONFERENCE ON TRADE AND DEVELOPMENT (2000) World Investment Report 2000. Cross-border mergers and acquisition and development. New York: United Nations, 2000. 